\title{
Photosensitized degradation of dinitrosalicylic acid by uranyl ions
}

\author{
A. A. I. Essawy ${ }^{1}$ and M. S. A. Abdel-Mottaleb ${ }^{2, \dagger}$ \\ ${ }^{1}$ Dept. Chem., Faculty of Science, Cairo University, Fayoum Branch \\ ${ }^{2}$ Photoenergy Center, Faculty of Science, Ain Shams University, Abbassia, Cairo, Egypt
}

\begin{abstract}
The photodegradation of dinitrosalicylic acid (DNS) by photoexcited uranyl ion was studied in aqueous solutions. The failure of DNS to degrade directly with light highlights the importance of the photoexcited uranyl ion in controlling the photochemical processes. Fluorescence quenching studies showed that an electron-transfer process from the DNS to the excited uranyl ion is involved leading to the formation of $\mathrm{UO}_{2}{ }^{+} / \mathrm{DNS}{ }^{\bullet+}$ radical pair complex as an initial step. Illumination of the $\mathrm{UO}_{2}{ }^{2+} / \mathrm{DNS}$ solution in presence of oxygen results in mineralization of DNS. The results are explained on the basis of a catalytic cycle involving $\mathrm{UO}_{2}{ }^{2+}$ ion and molecular oxygen that generates reactive superoxide $\mathrm{O}_{2}{ }^{\bullet-}$ anion and its conjugate acid $\mathrm{HO}_{2}{ }^{\circ}$. The efficiency of the photocatalytic cycle is enhanced markedly by addition of dilute $\mathrm{NaOH}$ solution.
\end{abstract}

\section{INTRODUCTION}

DNS is commonly used as an important analytical reagent in biochemistry for calculation of enzyme activity and for determination of reducing sugar. DNS is considered toxic (USA) or harmful (EU) by inhalation, in contact with skin and if swallowed. It belongs to explosives. However, the increasing awareness of the possible environmental effects of this compound and its derivatives has led to the demand for limiting their usage and for the development of new methods of treating contaminated waters in which they are present. Because excited uranyl ion, ${ }^{*} \mathrm{UO}_{2}{ }^{2+}$, is a strongly oxidizing species $\left(E^{o}=+2.6 \pm 0.1 \mathrm{~V}\right)[1,2]$, it has recently been used to oxidize a variety of substrates [3, 4]. With phenols and derivatives, reaction has been shown to occur by a dynamic process $[5,6]$ involving intermediate phenoxyl radical-uranium $(\mathrm{V})$ radical pairs. A catalytic cycle for chlorophenols photooxidation involving uranyl ion and molecular oxygen has been proposed [5].

The development of novel methods for photomineralization of toxic compounds, such as dinitrosalicylic acid, is of considerable interest and importance. In this paper we report on the study of the excited state interactions between uranyl ion and DNS and the kinetics of the catalytic photodegradation of DNS by uranyl ion.

\section{MATERIALS AND METHODS}

2-Hydroxy-3,5-Dinitro Benzoic acid (DNS) supplied from Merck was recrystalized (m.p. $=171-173^{\circ} \mathrm{C}$ ) from a mixture of methanol and benzene.

Uranyl nitrate hexahydrates of analytical grade was used. The $\mathrm{pH}$ of solutions has been adjusted using traces of $\mathrm{HClO}_{4}$ and $\mathrm{NaOH}$ solutions.

\footnotetext{
† E-mail: solar@photoenergy.org
}

The irradiation source was a $75 \mathrm{~W}$ Xenon arc lamp (PTI-LPS-220 photon technology international) operated at $70 \mathrm{~W}$. The light intensity was measured using radiometer (IL1700 international light) equipped with appropriate solar-blind vacuum photodiodes head and was found to be $13.2 \mathrm{~W} / \mathrm{cm}^{2} \cdot \mathrm{min}$.

The absorption spectra have been recorded using He $\lambda$ ios $\alpha$ Unicam Spectrophotometer. Fluorescence measurements have been done using RF-5301 PC SHIMADZU Spectrofluorophotometer. Irradiation processes have been carried out for oxygen saturated solutions in a quartz cuvette. Digital pH meter was used to measure the $\mathrm{pH}$ of solutions. TOC was measured on a calibrated total organic carbon analyzer Ionics Model 1555B. The data have been analyzed using Origin 7.0 scientific Graphing and analysis software from OriginLab.

\section{RESULTS AND DISCUSSION}

3.1. Spectroscopic properties. The absorption and emission spectra of uranyl nitrate in bidistilled water are shown in Figure 1. DNS aqueous solution does not fluoresce. At room temperature, the absorption spectra of mixtures of $\mathrm{UO}_{2}{ }^{2+}\left(\left[\mathrm{UO}_{2}{ }^{2+}\right] \geq 1.0 \times 10^{-2} \mathrm{M}\right)$ with the DNS ([DNS] $<5.0 \times 10^{-3} \mathrm{M}$ ) were shown to be equal to the sum of the component spectra, showing that under this experimental condition no significant ground-state interaction between uranyl ion and DNS was present. Fluorescence quenching data, which will be presented later, support this experimental finding. However, it should be noted that under conditions where the concentration of DNS was higher than that of uranyl ion (i.e., [DNS]/[ $\left[\mathrm{UO}_{2}{ }^{2+}\right]>1$ ), an increase in absorbance over the whole absorption spectrum was observed. This phenomenon can be related to that previously reported for complexing of the phenolic hydroxyl group with $\mathrm{UO}_{2}{ }^{2+}$ [7]. 


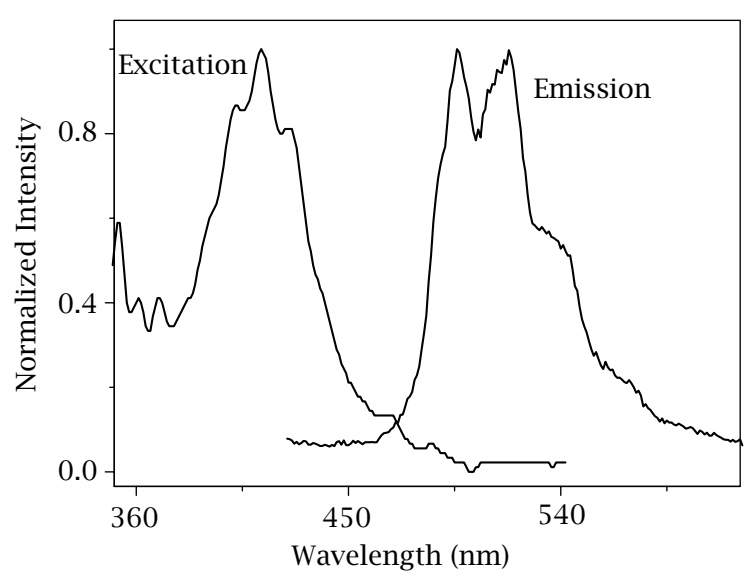

Figure 1. Normalized excitation (absorption) and emission (at $\lambda_{\mathrm{exc}}=413 \mathrm{~nm}$ ) spectra of $0.01 \mathrm{M}$ aqueous uranyl nitrate.

3.2. Fluorescence quenching of ${ }^{*} \mathrm{UO}_{2}{ }^{2+}$. Fluorescence spectrum (at excitation wavelength $\lambda_{\mathrm{exc}}=$ $413 \mathrm{~nm}$ ) of aqueous solution of uranyl ion is quenched by the addition of different concentrations of aqueous DNS, as shown in Figure 2. Assuming collisional (dynamic) quenching, the decrease in intensity was described by Stern-Volmer equation:

$$
\mathrm{F}_{0} / \mathrm{F}=1+\mathrm{K}_{\mathrm{sv}}[\mathrm{Q}]=1+\mathrm{k}_{\mathrm{q}} \tau_{0}[\mathrm{Q}]
$$

where $F_{0}$ is the intensity of the fluorescence of uranyl ion in absence of DNS; F = intensity of the fluorescence of the uranyl ion at a given concentration of DNS, $\mathrm{K}_{\mathrm{sv}}$ is the Stern-Volmer quenching constant, $\mathrm{k}_{\mathrm{q}}$ is the bimolecular quenching constant and $\tau_{0}$ is the lifetime of uranyl ion. Figure 3 represents the obtained least squares Stern-Volmer linear plots of $\left\{\left(\mathrm{F}_{0} / \mathrm{F}\right)-1\right\}$ versus the concentration of DNS [Q]. $\left\{\mathrm{K}_{\mathrm{sv}}=9.6 \times 10^{3} \mathrm{M}^{-1}\right.$ and $\mathrm{k}_{\mathrm{q}}=8.7 \times 10^{8} \mathrm{M}^{-1} \mathrm{~s}^{-1}$ where $\tau_{0}=11 \times 10^{-6} \mathrm{~s}$ [ [8].

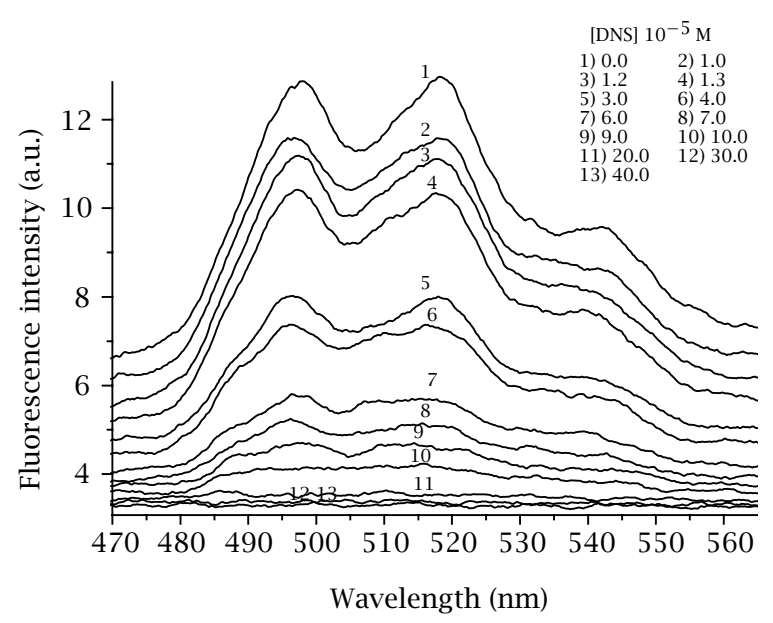

Figure 2. Fluorescence spectrum of (1) (0.01M) aqueous solution of $\mathrm{UO}_{2}\left(\mathrm{No}_{3}\right)_{2} .6 \mathrm{H}_{2} \mathrm{O}$ and quenching effect of adding aqueous solution of DNS of different concentrations.

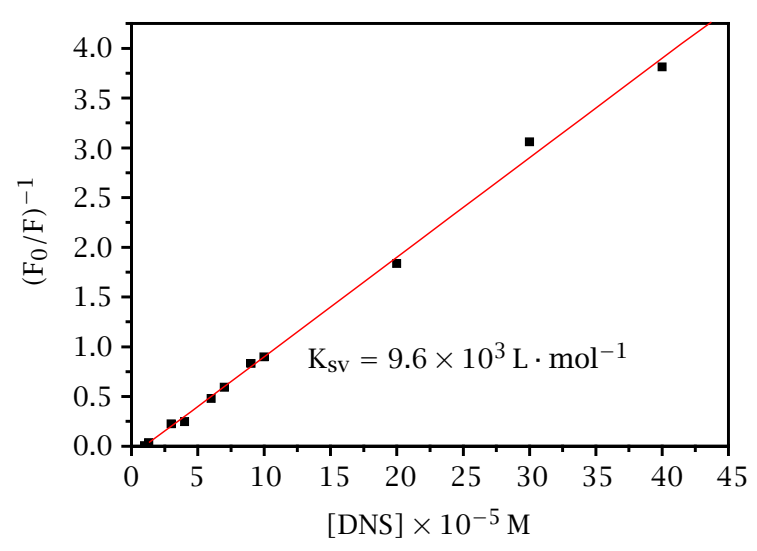

Figure 3. Linear Stern-Voelmer plot $(r=0.999)$ of data of Figure 2. analytical $\lambda=497 \mathrm{~nm}$.

The results verify diffusion controlled excited state interactions between ${ }^{*} \mathrm{UO}_{2}{ }^{2+}$ and DNS leading to the formation of complex radical pairs similar to those reported previously between ${ }^{*} \mathrm{UO}_{2}{ }^{2+}$ and chlorophenols or naphthalene based on electron-transfer process [5] (Scheme 1-A).

3.3. Catalytic Photodegradation of DNS. There is no remarkable variation observed in the absorption spectrum of DNS solution under white light illumination for 85 minutes; a result that verifies high photostability of DNS solution in absence of uranyl ion.

Upon irradiation of aqueous solution of a mixture of uranyl nitrate $(0.01 \mathrm{M})$ and DNS $\left(<10^{-5} \mathrm{M}\right)(\mathrm{pH}=4.0)$ a remarkable change in the absorption spectrum of the mixture DNS and uranyl ion was observed due to photodegradation of DNS, Figure 4. Moreover, the $\mathrm{pH}$ of the final solution is dropped to 2.3 indicating $\mathrm{H}^{+}$generation. Complete disappearance of the absorption spectrum of DNS was noticed after about 120 minutes of illumination. The data fits first order rate law, with rate constant of $4.7 \times 10^{-1} \mathrm{~s}^{-1}$.

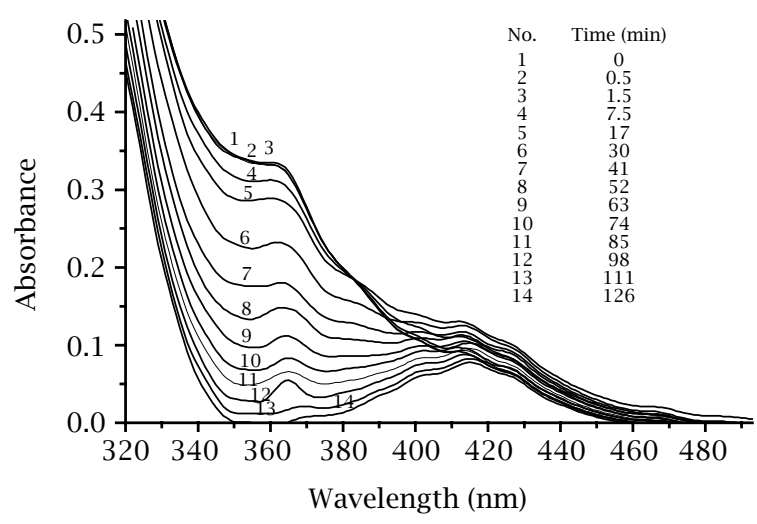

Figure 4. Effect of time of illumination on the absorption spectrum of aqueous solution of the mixture $\left[\mathrm{UO}_{2}\left(\mathrm{NO}_{3}\right)_{2}\right.$. $6 \mathrm{H}_{2} \mathrm{O}(0.01 M)$ and DNS $\left.\left(1.3 \times 10^{-5} M\right)\right]$. 
The oxidation action of ${ }^{*} \mathrm{UO}_{2}{ }^{2+}$ was found to be operative in acidic solution leading to a remarkable degradation of DNS. Total organic carbon measurements indicated the complete mineralization of the DNS after 120 minutes of illumination which is attributed to the presence of ${ }^{*} \mathrm{UO}_{2}{ }^{2+}$ which acts as potent oxidant [5].

This catalytic action has been discussed previously in the oxidation of chlorophenols by photoexcited uranyl ion where a clean electron-transfer process from the chlorophenols to the excited uranyl ion is involved [5]. This is suggested to lead to the formation of a U(V)/chlorophenoxyl radical pair complex. In the presence of oxygen the quantum yields of disappearance of chlorophenol and of photoproduct formation increased. This leads to the conclusion that oxygen favors reaction with uranium(V) and/or the uranium(V)phenoxyl radical pair, leading to the formation of the superoxide anion and its conjugate acid, $\mathrm{HO}_{2}{ }^{\bullet}$ which then regenerate $\mathrm{UO}_{2}{ }^{2+}$ [5]. Similarly, a catalytic cycle for DNS photooxidation involving uranyl ion and molecular oxygen is proposed: Scheme 1-B.<smiles></smiles>

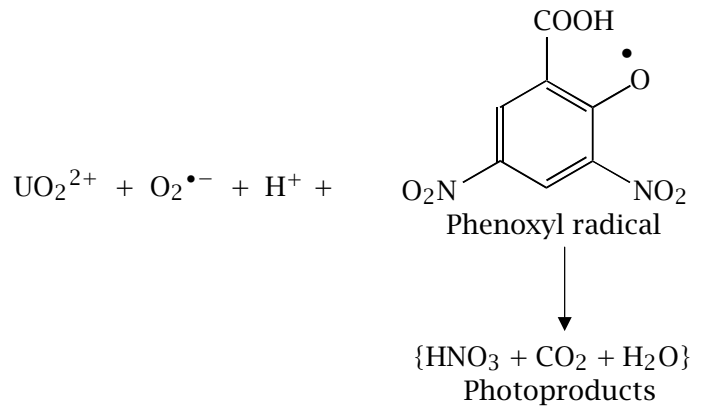

Scheme 1.

Astonishingly, the catalytic photodegradation rate for the DNS in presence of traces of $\mathrm{NaOH}$ solution (of initial $\mathrm{pH}=9.0$ ) was faster by one order of magnitude than that performed without adding $\mathrm{NaOH}$ solution. The measured $\mathrm{pH}$ of the completely degraded solution was 2.99. These results could be due to the formation of the less stable sodium salt of the phenoxyl radical of the DNS and/or the more reactive $\mathrm{NaO}_{2}{ }^{\bullet}$ species. Adding $\mathrm{NaOH}$ competes with $\mathrm{O}_{2}{ }^{-}$for the $\mathrm{H}^{+}$generated leading to more efficient photodegradation of the initially formed $\mathrm{DNS}^{\bullet} \mathrm{Na}^{+}$by $\mathrm{O}_{2}{ }^{\bullet-}$.

DNS is quite likely to be ionized under the experimental conditions used. This can complex directly with the excited uranyl, and photooxidation proceeds via an intramolecular reaction involving oxidative decarboxylation in addition to the proposed intermolecular electron transfer reaction. The results noticed above in presence of traces of $\mathrm{NaOH}$ solution strongly suggest the importance of this alternative route.

Moreover, it is of interest to mention that repeating the experiment by addition of new DNS solution to the same old solution containing uranyl ion results in the complete mineralization of DNS without noticeable change in the rate of photodegradation. The experiment was repeated up to five times without passivation of the catalytic activity of the uranyl ion.

\section{CONCLUSION}

Complete mineralization of DNS was achieved in an efficient photocatalytic cycle involving $\mathrm{UO}_{2}{ }^{2+}$ and molecular oxygen.

\section{ACKNOWLEDGEMENT}

A. A. I. would like to express his deepest gratitude and thanks to the Photoenergy Center for offering all experimental facilities.

\section{REFERENCES}

[1] V. Balzani, F. Bolletta, M. T. Gandolfi, and M. Maestri, Topics Current Chem. 75 (1978), 1.

[2] C. K. Jorgensen and R. Reisfeld, Struct. Bonding 50 (1982), 121.

[3] W. D. Wang, A. Bakac, and J. H. Espenson, Inorg. Chem. 34 (1995), 6034.

[4] A. Bakac and J. H. Espenson, Inorg. Chem. 34 (1995), 1730 .

[5] M. Sarakha, M. Bolte, and H. D. Burrows, J. Phys. Chem. A 104 (2000), 3142, and references therein.

[6] G. I. Sergeeva, A. K. Chibisov, L. V. Levshin, and A. V. Karyakin, J. Photochem. 5 (1976), 253.

[7] M. Bartusek and L. Sommer, J. Inorg. Nucl. Chem. 27 (1965), 2397.

[8] J. Wheeler and J. K. Thomas, J. Phys. Chem. 88 (1984), 750. 


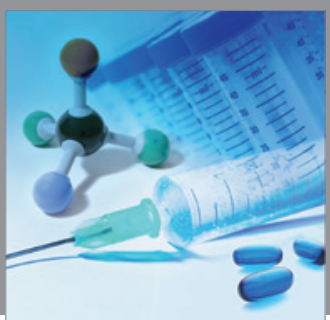

International Journal of

Medicinal Chemistry

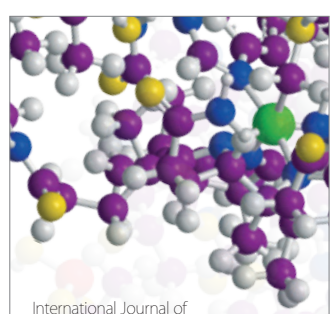

Carbohydrate Chemistry

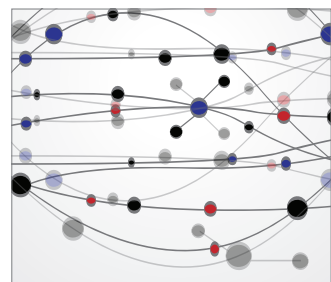

The Scientific World Journal
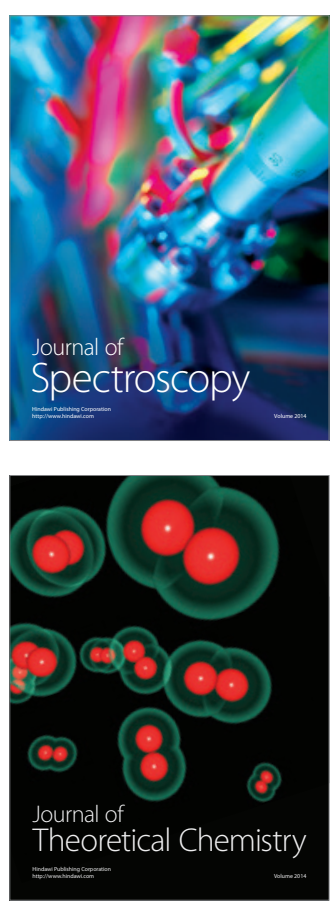
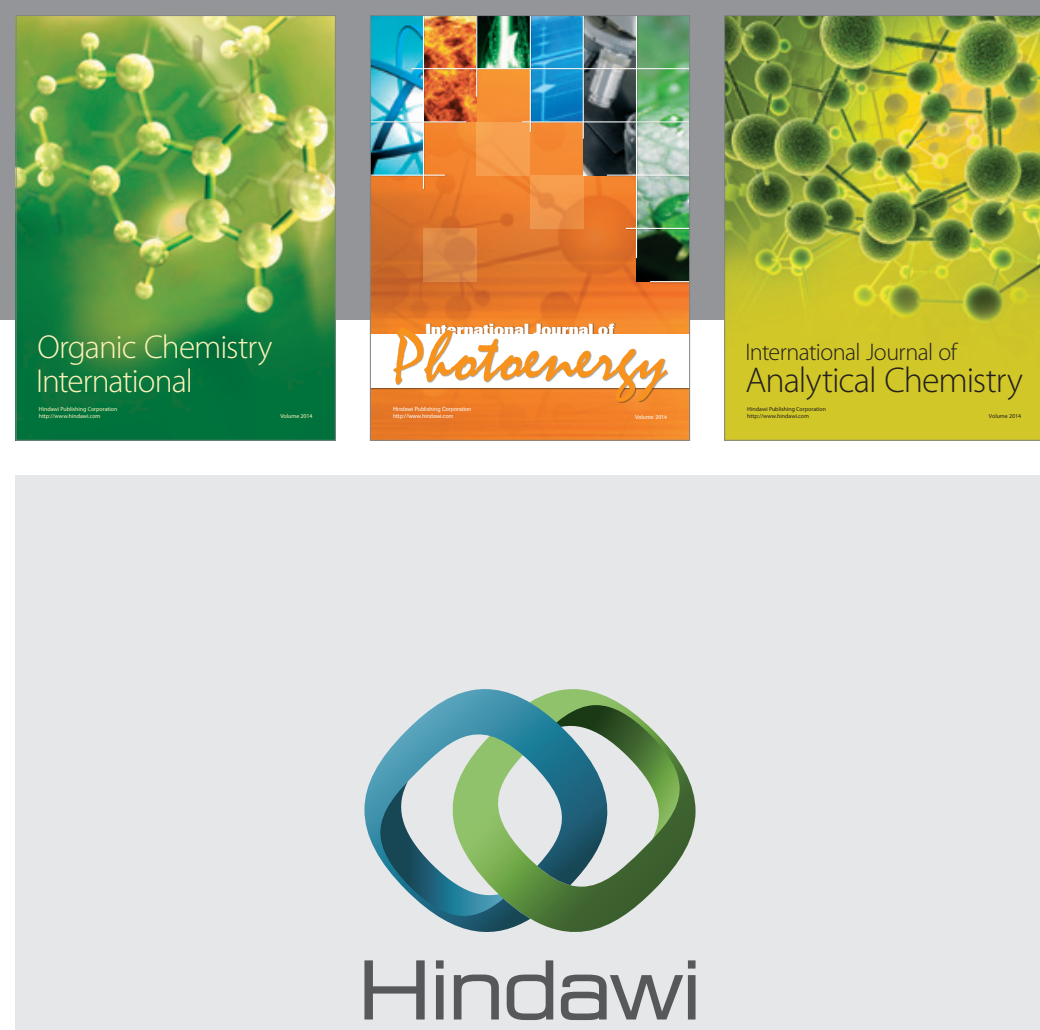

Submit your manuscripts at

http://www.hindawi.com
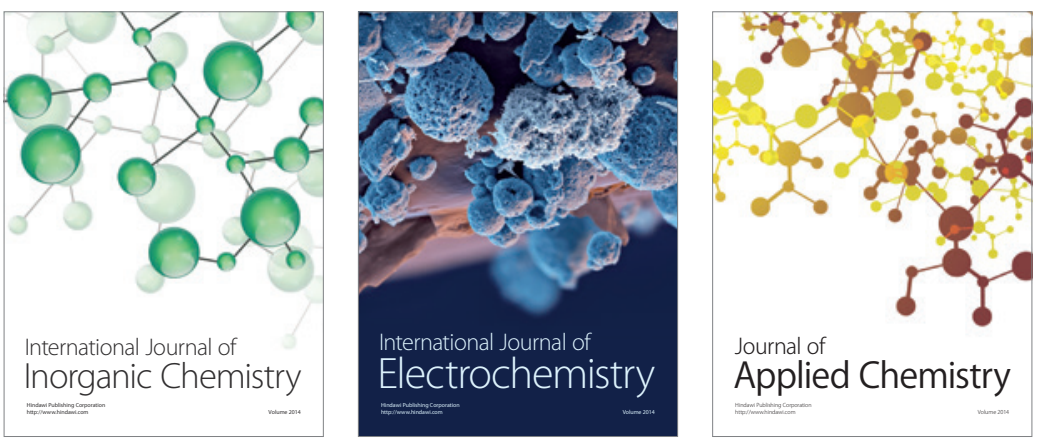

Journal of

Applied Chemistry
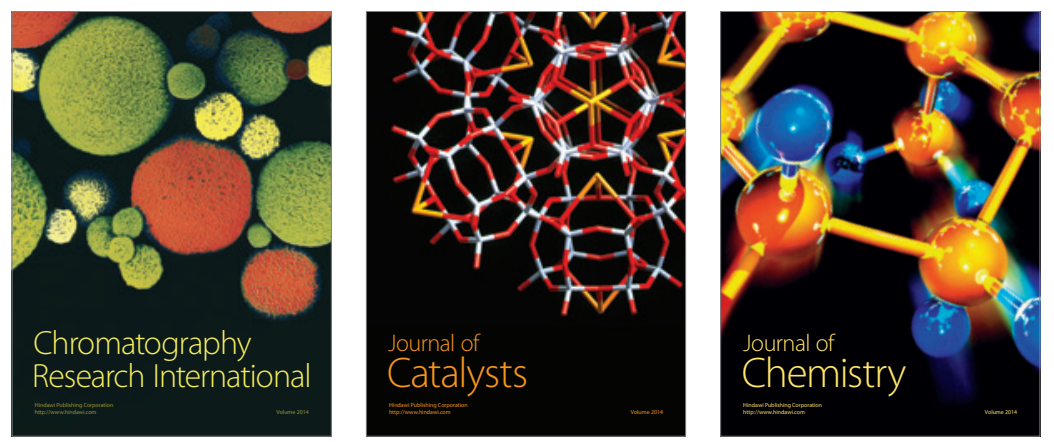
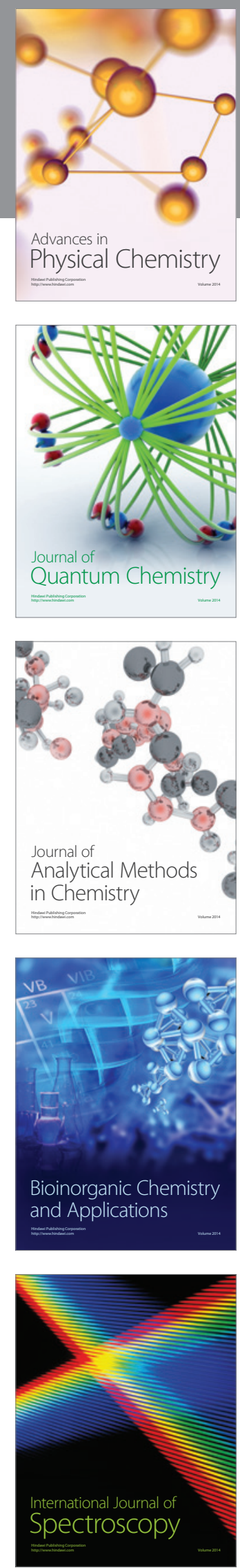